\title{
Professionalism: the historical contract
}

$\mathrm{D}$ eath and taxes may be life's only guarantees, but suffering is also a safe bet. Who hasn't fallen ill or ached from injury or endured pain of some sort? It should come as no surprise, then, that people who relieve others' misery have held high standing in their communities throughout history.

The role of the healer - tasked with setting broken bones, stitching open wounds and administering medicine is valued by every society on earth. In general, those who take on this role receive trust, respect, autonomy, social status and financial reward. But these good things come at a cost.

Society has always expected much of those put in charge of citizens' health. Healers are to be altruistic, moral, objective, competent, accountable and accessible. This social contract - what patients expect from doctors and vice versa changes over time but has always been central to the medical profession.

"The essence of professionalism is a bargain between society and medicine," says Dr. Richard Cruess, a professor of surgery at McGill University's Centre for Medical Education in Montréal, Quebec.

In the Western world, the roots of the the healer date to Hellenic Greece and the Hippocratic Oath. For centuries after, there was no medical profession to speak of, but rather individuals who independently tended to the sick. "The role of the healer has remained fairly constant, but the concept of professionalism has changed in response to societal and professional needs," Cruess and colleagues have suggested (Lancet 2000;356:156-9).

As medicine became more complex and demands from society more intense, there grew a need for structure and organization. This was accomplished by delivering health services according to the concept of a profession. The idea of establishing professions to deliver complex services dates to medieval Europe. By the mid-nineteenth century, the concept had morphed well beyond the medieval notion of a guild. "The modern professions were established in the mid-

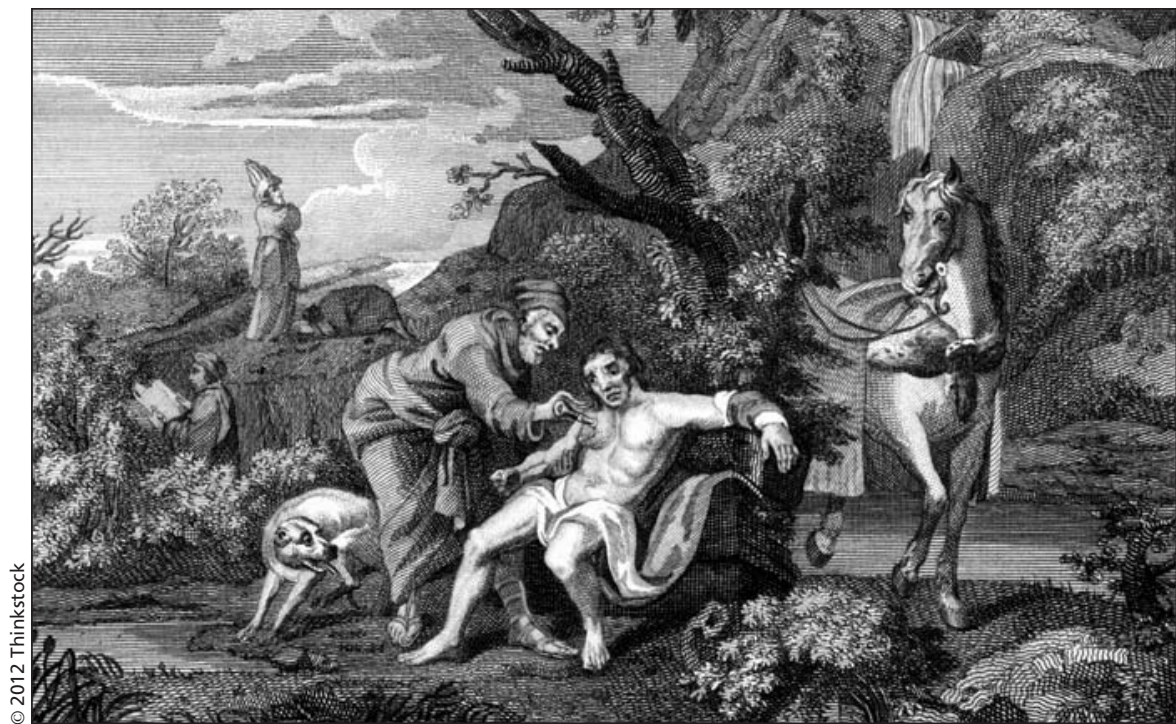

The notion that doctors are primarily good Samaritans motivated by altruism is viewed by some with increasing skepticism.

nineteenth century, when laws governing licensure granted a monopoly over practice, with a clear understanding that professions would be altruistic and moral and would address society's concerns," Cruess and colleagues have noted $(J$ Bone Joint Surg 2000;82:1189-94).

There are several widely accepted tenets of a profession. One is that members require specialized knowledge that takes long periods of intense study to acquire. As such, a profession is granted monopoly over how that knowledge is used and taught. Because the knowledge is largely inaccessible to laymen, a profession is also granted autonomy to set standards, self-regulate and discipline unprofessional behaviour. The condition for these privileges: professions must serve the public in an altruistic manner.

Sociologists have been studying various professions for more than a century. Interest in the medical profession, specifically, increased in the 1930s. Though it was recognized that, like all humans, doctors aren't above selfishness, academics found that the profession was held in high regard. "The early literature was largely favourable," wrote Cruess and his colleagues. "There was faith in the virtue, morality, and service commitment of pro- fessionals, although the tension between self-interest and altruism was identified."

By the 1960s, however, attitudes about doctors had begun to sour. Medicine was becoming increasingly complex. There were new specialties and technologies and financial models. The public found the field too confusing. Tension had also arisen over the rising cost of health care, the decrease in interest among doctors about their patients' emotional lives and the preoccupation of physicians to spend time in laboratories rather than with patients, anthropologist and sociologist Murray Wax suggested ( $\mathrm{J}$ Health Hum Behav 1962;3:152-6).

Within a decade, society entered a period of deconstruction. People were more cynical and questioned authority and expertise. Respect for all professions took a dive. The notion that doctors were altruistic was viewed with increased skepticism, and their professionalism was no longer assumed.

Still, despite growing discontent, the general attitude within medicine was that professionalism came automatically - a mere byproduct of medical education. "The degree (M.D.) defined and established everything. In turn, carrying out one's clinical work in a 'conscientious 
manner' established that one was practicing medicine in a professional manner. ... physicians began to treat professionalism as something they were owed by a "grateful' public," Frederic Hafferty, professor of medical education and associate director of the program in professionalism and ethics at the Mayo Clinic in Rochester, Minnesota, and colleagues wrote in "Two Cultures: Two Ships: The Rise of a Professionalism Movement Within Modern Medicine and Medical Sociology's Disappearance from the Professionalism Debate," chapter 11 of the Handbook of the Sociology of Health, Illness, and Healing (www.springerlink.com/content /q831w4579306163j).

But that attitude changed in the early 1980s, which marked the beginning of a bull market that stretched for nearly two decades. Suddenly, billions of dollars were being poured into pharmaceutical companies, medical device manufacturers and other areas of health care, transforming it into big business and a major part of the economy.

"When I started out, there were no for-profit hospitals. There was no private, for-profit health insurance. Nobody referred to medicine as an industry," says Dr. Arnold Relman, professor emeritus of medicine and social medicine at Harvard Medical School in Boston, Massachusetts, and former editor in chief of the New England Journal of Medicine, who graduated from medical school in 1946.
In the United States, medicine entered a corporate era. Doctors were making more money. Some became entrepreneurs, raising concerns that profits were trumping professionalism. Others worried that professionalism's greatest threat was managed-care operators robbing their autonomy. "Managed care presented issues for doctors in so far as they found that managed-care operations were micromanaging them," says Michael Yeo, a philosophy professor at Laurentian University in Sudbury, Ontario. "Their relationships with patients became filled with this third party looking over the doctors' shoulders."

A new professionalism movement arose to counter the influence of managed-care organizations. By stressing they were professionals, not mere employees, physicians could create rules about what they could and could not be forced to do. "If you can say it's against my professional ethics, that is a stronger case than saying it's against my morals," says Yeo. "There is a difference between being an employee and being a member of a profession. You are less malleable."

This rekindled passion for professionalism, now two decades old and still going strong, has led to many changes in medicine. Medical schools now teach professionalism to students. Academic physicians write paper after paper on the topic. Health care organizations have attempted to formalize in words the social contract between medicine and society that for centuries had been acknowledged but unwritten. Much of this effort was fueled by a longing to return to what many doctors viewed as the golden age of medicine, before corporations and governments took over.

"The nostalgia part was fuelled by how medicine chose to define the problem," says Hafferty. "How do we solve the problem? By recommitting ourselves to those traditional values. Medicine came up with a variety of ways of institutionalizing this. They created codes and charters and competencies and curriculum - all these 'c' words."

Where will discussions of medical professionalism go from here? Of late, there has been much interest in the professional behaviour of physicians on social media. Will that still be a topic of interest in the future? No one knows that, of course. Until doctors start trading in their stethoscopes for crystal balls, there will be no consensus on future trends in professionalism.

"What's it going to be in five years?" says Hafferty. "The point is, whatever it is - whether it's duty hours or Facebook or something else - it's going to be an opportunity to engage in the critical question: What does it mean to be a good doctor?" - Roger Collier, CMAJ

CMAJ 2012. DOI:10.1503/cmaj.109-4230

\section{Professionalism: Can it be taught?}

$\mathrm{T}$ here's a saying in basketball: You can't teach height. Of course, there are many things that would provide advantages in life that can't be taught - competitiveness, intelligence, curiosity, creativity, stick-to-it-iveness. And we've all heard the one about old dogs and new tricks. Should medical professionalism be added to the list of unteachable subjects?

The medical profession, evidently, doesn't think so. Almost every medical professional body in North America considers professionalism an essential topic and has mandated that it be taught in faculties of medicine. The Accreditation
Council for Graduate Medical Education, responsible for accrediting residency and internship programs in the United States, considers it a core competency. Questions on professionalism appear on the Medical Council of Canada's licensing exam, completed by all Canadian undergraduate medical students.

Some doctors, however, wonder if professionalism can really be learned in the classroom. Many of the qualities required to meet the professional ideals of medicine go far beyond biological know-how. Selflessness, empathy, benevolence - these aren't exactly things one gleans from books. Medical professors can preach altruism, but no sermon can transform a student's personality. The challenge of teaching a medical student to be a "good" doctor is, in some ways, akin to that of teaching an individual to be a "good" person. It is, in short, challenging indeed.

Still, professionalism in medicine is too important not to include in medical curricula, especially considering the prevailing opinion that doctors are less altruistic and more financially driven now than they once were, says Dr. Richard Cruess, a professor of surgery at McGill University's Centre for Medical Education in Montréal, Quebec. 